\title{
THE EFFECT OF BETACYCLODEXTRIN ON THE SOLUBILITY AND DISSOLUTION OF SPIRONOLACTONE USING PHYSICAL MIXING AND CO-EVAPORATION METHODS
}

Khaled I. Saleh

Dept. of Pharmaceutics and Industrial Pharamcy, Faculty of Pharmacy, Al-Azhar University, Assiut Branch.

\begin{abstract}
Spironolactone is a steroidal drug acting as a specific aldosterone antagonist used as potassium sparing diuretic. It shows variable absorption and bioavailability due to its poor solubility. The objective of this study was to investigate the effect of betacyclodextrin (BCD) on the solubility and dissolution of spironolactone using physical mixing and coevaporation methods. The physical mixtures of different $w / w$ drug/carrier ratios $(1: 1,1: 2$ and 1:3) were prepared by simple mixing. Also co-evaporate systems containing $(1: 1,1: 2$ and 1:3) w/w drug/carrier ratios were prepared. The physicochemical characterization of the systems using differential scanning calorimetry (DSC) and powder X-ray diffraction was carried out to detect the interaction between the drug and the carrier, moreover, quantitative solubility and in-vitro dissolution studies of spironolactone alone and in physical mixtures or co-evaporates were studied in simulated gastric fluid (SGF) of $\mathrm{pH} 1.2$ and in simulated intestinal fluid (SIF) of $\mathrm{pH} 7.5$.

The reduction of drug peaks in X-ray diffraction pattern of the co-evaparate and the absence or reduction of drug peaks in DSC profile of the physical mixture and the coevaporate suggest the transformation of crystalline spironolactone into an amorphous form due to the inclusion complexation with betacyclodextrin. The study showed an increase in the solubility values and an improvement in the dissolution pattern of the drug in case of the physical mixtures and the co-evaporates.
\end{abstract}

\section{INTRODUCTION:}

Spironolactone is a renal competitive aldosterone antagonist in a class of pharmaceuticals called potassium sparing diuretics. It is used to treat heart failure, ascites in patients with liver disease, low-renin hypertension and hypokalemia (Rani et al., 2012). It is described as a light, cream-colored to light tan, crystalline powder with a faint to mild mercaptan-like odor, practically insoluble in water, soluble in alcohol and in ethyl acetate, freely soluble in chloroform and in benzene, and slightly soluble in methyl alcohol and fixed oils (USP XXIX, 2006). Spironolactone is absorbed rapidly and bound avidly to protein. But it does not show comprehensive therapeutic effect because of its poor solubility and dissolution, which leads to poor bioavailability of the drug (Ahuja et al., 2007). In the process of absorption of drug from oral route, dissolution is the rate limiting step for lipophilic drugs. Thus increasing the aqueous solubility and dissolution rate of spironolactone is of therapeutic importance (Kadir et al., 2012). The main technologies to achieve the enhanced oral bioavailability of drugs with poor aqueous solubility include the use of miconization, nanosizing, solid dispersions, cyclodextrins, solid lipid nanoparticles and other colloidal drug delivery systems such as mcroemulsions and self-emulsifying drug delivery systems (Fahr and Liu, 2007; Gomez-Orellana, 2005).

Cyclodextrins consisting of 6,7 and 8 glucopyranosyl units connected to $\alpha-1,4-$ glycosidic linkages are knoun as $\alpha, \beta$ and $\gamma$ cyclodextrins, respectively (Loftsson and 
Brewster, 1996). $\quad \beta$-cyclodextrins are 'bucket like' molecules; with a central cavity. The internal surface of the cavity is hydrophobic and the outer is hydrophilic. This permits the cyclodextrin to incorporate the nonpolar molecule or the nonpolar part of one molecule into the cavity, forming an inclusion complex resulting in better stability, high water solubility, increased bioavailability or decreased undesirable side effects (Rani et al., 2012; Duchene et al., 1999).

Solid dispersion system is defined as a dispersion of one or more active ingredient in an inert carrier at solid state prepared by the melting, solvent or melting solvent method (Kadir et al., 2012). Solid dispersions and solutions that are manufactured by the solvent evaporation method should realy be called coevaporates and not coprecipitates (Leuner and Dressman; 2000). Solid dispersion method has been widely employed to improve the dissolution rate, solubility and oral absorption of poorly water soluble drugs (Tanaka et al., 2006; Duncan, 2002).

The objective of this work was to prepare physical mixtures of spironolactone and $\beta$ cyclodextrin by simple mixing and co-evaportaes using solvent method of solid dispersion techniques to improve the solubility and dissolution of the drug.

\section{MATERIALS AND METHODS}

\section{Preparation of physical mixtures}

The physical mixtures of the drug and the carrier (BCD) in different drug/carrier ratios (1:1, 1:2 and 1:3) were prepared by simple mixing avoiding any grinding effect.

\section{Preparation of the co-evaporates:}

Co-evaporate systems containing $(1: 1,1: 2$ and 1:3) w/w drug/carrier ratios were prepared using solvent method of solid dispersion techniques. The calculated amount of spironolactone was dissolved in ethanol and the equivalent amount of BCD was dissolved in distilled water, then mixed together till clear solution was obtained. The solvents were removed by keeping the solution in a vacuum oven at $40{ }^{\circ} \mathrm{C}$ till complete drying. The samples were then scrapped and powdered, then assayed for their drug content.

\section{Characterization of the prepared physical mixtures and co-evaporates}

\section{Determination of the drug content}

An accuratelly weighed sample of the co-evaporate equivalent to $7.5 \mathrm{mg}$ of the drug was dissolved in $700 \mathrm{ml}$ of simulated gastric fluid (SGF) using dissolution apparatus vessel at $37 \pm 0.5{ }^{\circ} \mathrm{C}$ and $75 \mathrm{rpm}$ for 5 hours. The concentration of spironolactone was determined spectrophotometrically at $238 \mathrm{~nm}$. Each experiment was performed three times and the mean was calculated in each case.

\section{Differential scanning calorimetry}

DSC was performed using DSC-60 Shimadzu instrument under the following conditions; sample weight range of $1-4 \mathrm{mg}$, heating rate of $10 \% \mathrm{~min}, \mathrm{~N}_{2}$ purge rate of 20 $\mathrm{ml} / \mathrm{min}$ using aluminum pan hermetically sealed. The instrument was calibrated for temperature and energy with pure indium $\left(99.999 \%\right.$, melting point $156.6^{\circ}$ and transition energy $28.45 \mathrm{~J} / \mathrm{g}$ ). Thermal analysis was carried out using TA 60 PC system with Shimadzu software program. 


\section{X-ray diffractometry}

The X-ray diffraction patterns of the selected samples were obtained using a computer Philips operating in two modes using copper tube radiation. A $\mathrm{Cu}$ target tube operated at a voltage of $40 \mathrm{KV}$ and a current of $30 \mathrm{~mA}$ and a single crystal graphite monochromator were employed. An attached microprocessor utilizes a special software program to analyze peak position and intensities. Standard polycrystalline silicone was used to calibrate the equipment.

\section{Quantitative solubility:}

Quantitative solubility was determined by the equilibrium solubility method, which employs a saturated solution of the material in the solvent for a prolonged period until equilibrium is achieved.

For the determination of solubility, excess of spironolactone, its physical mixtures and its co-evaporates was placed in contact with $30 \mathrm{ml}$ of solvent (SGF pH 1.2 or SIF pH 7.5) in beakers, then covered with aluminum foil. The beakers were shaken $100 \mathrm{rpm}$ for 5 hours at $37 \pm 0.5{ }^{\circ} \mathrm{C}$. It was found that equilibrium solubility was achieved by this period. After filtration, the concentration of drug in the saturated solution was determined spectrophotometrically at $238 \mathrm{~nm}$ after appropriate dilution with the solvent used. Each experiment was preformed three times and the mean was calculated in each case.

\section{In-Vitro dissolution studies:}

The dissolution of the drug alone, from its physical mixtures and from its co evaporates was carried out using USP paddle dissolution apparatus. The dissolution medium was $900 \mathrm{ml} \mathrm{SGF} \mathrm{pH} 1.2$ or SIF pH 7.5, maintained at $37 \pm 0.5{ }^{\circ} \mathrm{C}$. The paddles were positioned $2.5 \mathrm{~cm}$ from the bottom of the vessel and rotated at a speed of $75 \mathrm{rpm}$. For the test, accurately weighed amount equivalent to $25 \mathrm{mg}$ of the drug and prefilled in a hard gelatin capsule was transferred to the stirred dissolution medium in each vessel. At time intervals, $5 \mathrm{ml}$ samples were withdrawn by a pipette fitted with a cotton plug at its terminal end. Equal volume of fresh dissolution medium was added to the dissolution medium so as to keep the volume of the dissolution medium constant. The absorbance of the samples was measured spectrophotometrically at $238 \mathrm{~nm}$. Each experiment was performed three times and the mean was calculated in each case. The standard curve of spironolactone in SGF or SIF (according to the fluid used in dissolution) was used to determine the amount of drug dissolved. The cumulative amount of drug was calculated to compensate for the previously withdrawn samples.

\section{RESULTS AND DISCUSSION}

\section{Determination of the drug content:}

Table (1): shows the results of drug content determination. The drug content was 102.03, 106.27 and $100.30 \%$ for $1: 1,1: 2$ and 1:3 w/w (drug: carrier) co-evaportes, respectively.

Table (1): Drug content for spironolactone-BCD, co-evaporates.

\begin{tabular}{|c|c|c|c|}
\hline $\begin{array}{c}\text { Drug: carrier } \\
\text { ratio }\end{array}$ & $\begin{array}{c}\text { Theoretical drug } \\
\text { content }(\mathrm{mg})\end{array}$ & $\begin{array}{c}\text { Actual drug content } \\
(\mathrm{mg})\end{array}$ & Drug content \% \\
\hline $1: 1$ & 7.5 & 7.65 & 102.03 \\
\hline $1: 2$ & 7.5 & 7.97 & 106.27 \\
\hline $1: 3$ & 7.5 & 7.52 & 100.30 \\
\hline
\end{tabular}




\section{Differential scanning calorimetry:}

DSC analysis of plain drug, carrier, physical mixture and co-evaporate is shown in Figure (1). The DSC chart of plain drug exhibited three endothermic peaks at 133.71, 218.11 and $222.57^{\circ} \mathrm{C}$. The DSC chart of both carrier and physical mixture showed no peaks. The DSC chart of the co-evaporate exhibited a shallow exothermic peak at $230.64^{\circ}$ C. These results may be attributed to the inclusion complexation and transformation of drug to amorphous state.

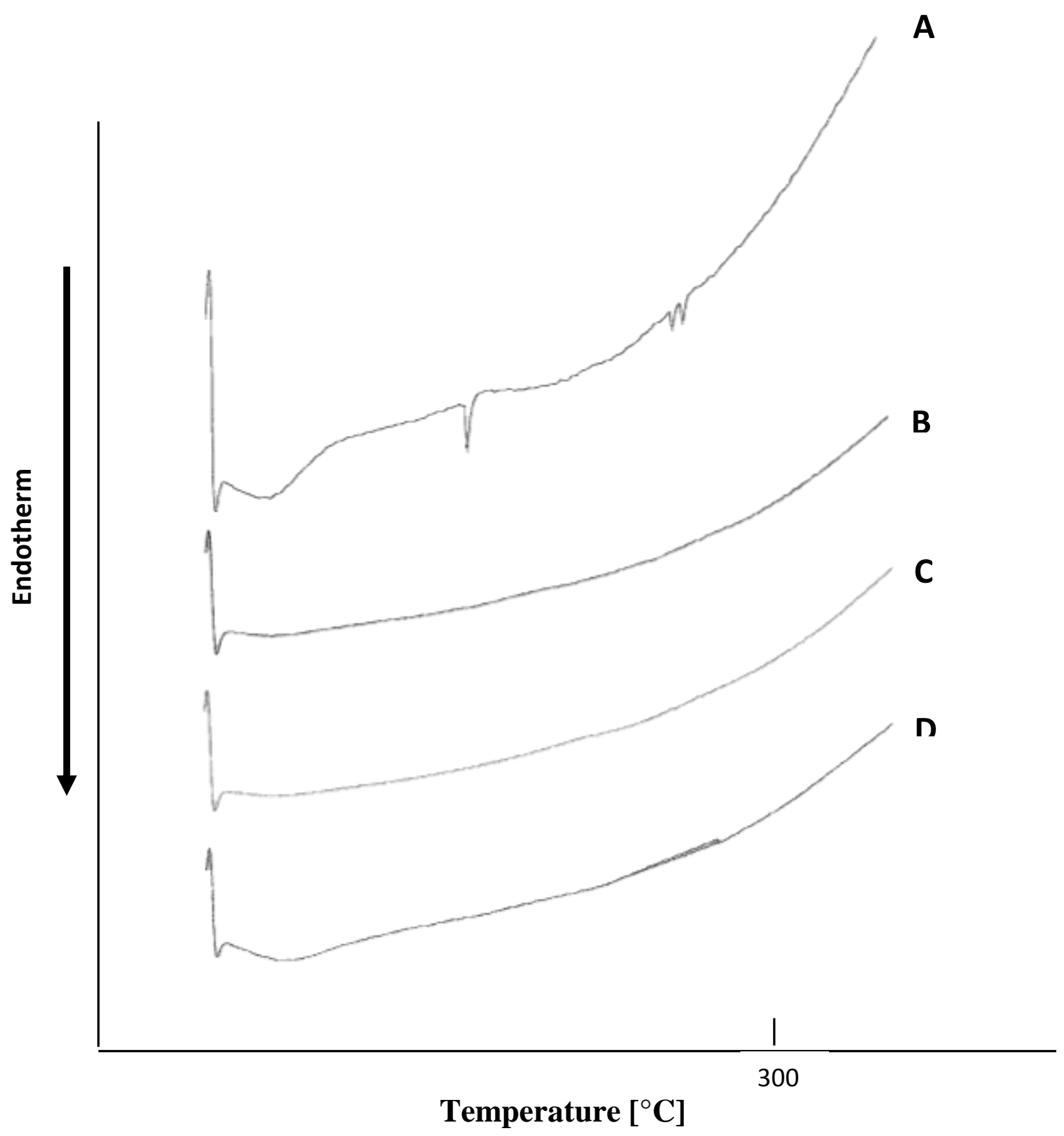

Figure (1): DSC thermograms of A- Plain drug, B- Carrier, C- Physical mixture and D- Coevaporate. 

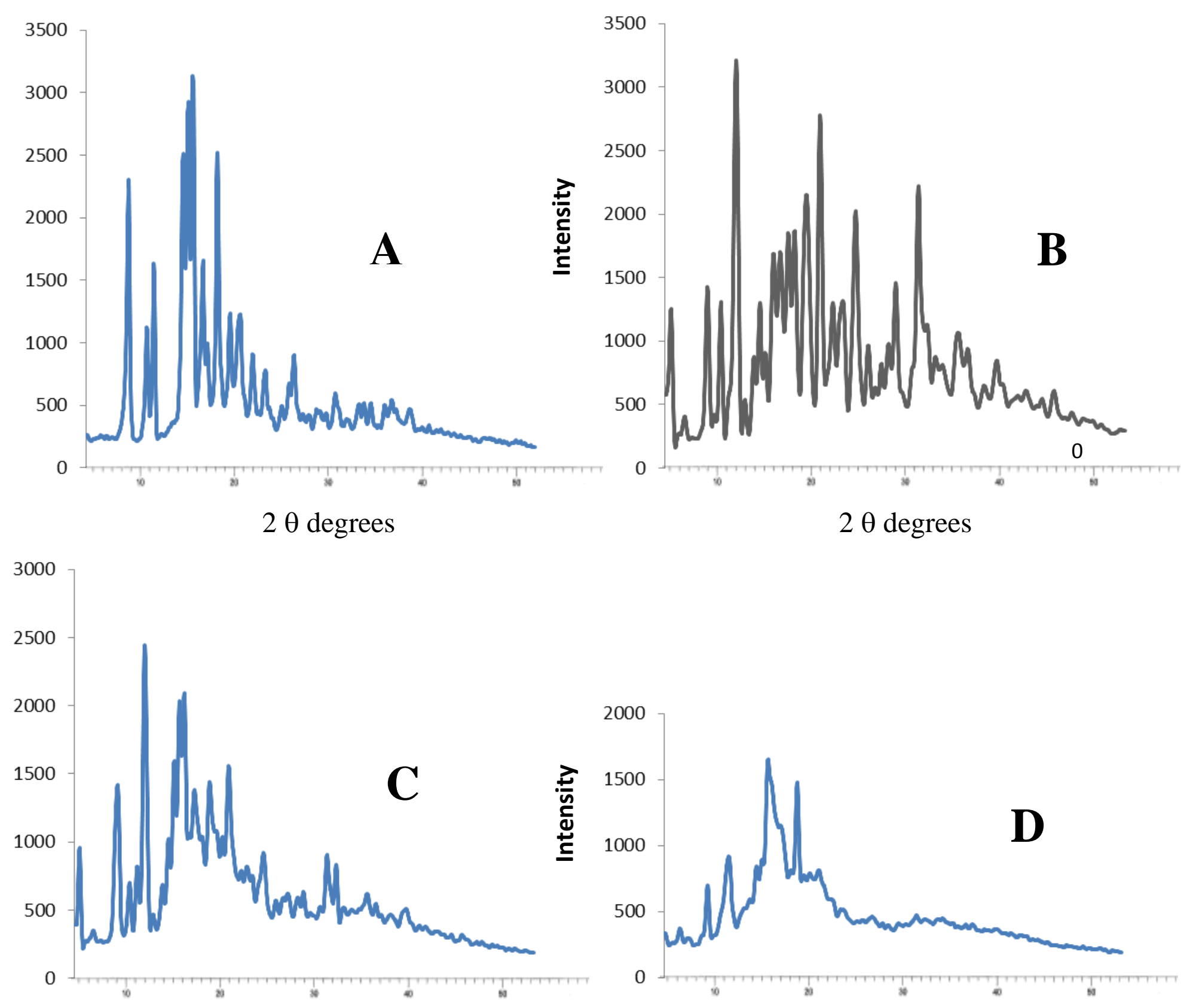

$2 \theta$ degrees

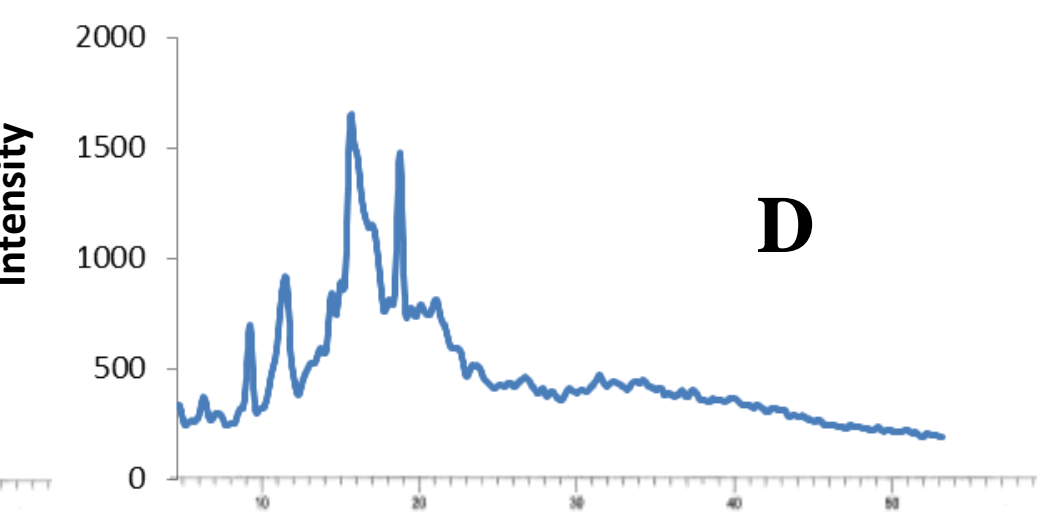

$2 \theta$ degrees

Figure (2): X-ray diffraction patterns of A-Plain drug, B-Carrier, C-Physical mixture and DCo-evaporate

\section{X-ray diffractometry}

X-ray diffraction technique was utilized to study the crystallographic nature of plain drug, carrier, physical mixture and co-evaporate.

The major X-ray diffraction peaks of spironolactone were observed at $2 \theta$ of 9.21 , 16.06, 16.72, 17.26 and 20.34 with relative intensities of 73, 80, 93, 100 and 80, respectively. Chart D (figure (2)) of the co-evaporate showed smaller characteristic peaks 
than those of the plain drug or the carrier that may be attributed to incomplete transformation of the drug to the amorphous state as a result of inclusion complexation. Similar results were obtained by Puckhraj Chhaprel et al., (2012).

\section{Quantitative solubility:}

The solubility values of spironolactone, its physical mixtures and its co-evaporates were calculated using the equilibrium solubility method. As it is shown in table (2) and figure ( $3 \& 4$ ), the solubility of plain drug was $39.36 \mu \mathrm{g} / \mathrm{ml}$ in SGF and $29.68 \mu \mathrm{g} / \mathrm{ml}$ in SIF. In case of physical mixture the solubility was $84.39,135.319$ and $113.06 \mu \mathrm{g} / \mathrm{ml}$ for $1: 1,1: 2$ and 1:3 drug/carrier ratios, respectively in SGF, where it was 112.23, 111.87 and 116.31 $\mu \mathrm{g} / \mathrm{ml}$ for $1: 1,1: 2$ and $1: 3 \mathrm{drug} /$ carrier ratios, respectively in SIF. In case of co-evaporates, the solubility was $66.04,91.36$ and $85.90 \mu \mathrm{g} / \mathrm{ml}$ for $1: 1,1: 2$ and $1: 3 \mathrm{drug} /$ carrier ratios, respectively in SGF, where it was $94.05,93.36$ and $96.81 \mu \mathrm{g} / \mathrm{ml}$ for $1: 1,1: 2$ and $1: 3$ drug/carrier ratios, respectively in SIF. These results show a significant increase in the solubility values of the physical mixtures and the co-evaporates compared to the solubility of the drug alone. The increased solubility of the drug in case of the co-evaporates may be attributed to the fact that a portion of the drug has been transformed from the crystalline state to the amorphous one as a result of inclusion complexation. The increased solubility of spironolactone from physical mixtures may be due to the fact that as the soluble carrier dissolves, the insoluble drug is exposed to dissolution medium as very fine particles leading to an increase in surface area and also the hydrophilic carrier enhances wetting characteristics of the drug (Purvis et al; 2006, Yonemochi et al; 1999, Chow et al; 1995). The presence of carrier may also prevent aggregation of fine drug particles, thereby providing a larger surface area for dissolution (Kadir et al; 2012).

Table (2): Solubility of spironolactone, its physical mixtures and its co-evaporates in SGF and SIF at $37 \pm 0.5^{\circ} \mathrm{C}$.

\begin{tabular}{|c|c|c|c|c|c|c|c|}
\hline \multirow{3}{*}{ Medium } & \multicolumn{9}{|c|}{ Solubility $\mu \mathrm{g} / \mathrm{ml}$} \\
\cline { 2 - 8 } & \multirow{2}{*}{ Plain drug } & \multicolumn{3}{|c|}{ Physical mixture } & \multicolumn{3}{c|}{ Co-evaporate } \\
\cline { 2 - 8 } & & $1: 1$ & $1: 2$ & $1: 3$ & $1: 1$ & $1: 2$ & $1: 3$ \\
\hline SGF & 39.36 & 84.39 & 135.19 & 113.06 & 66.04 & 91.36 & 85.90 \\
\hline SIF & 29.68 & 112.23 & 111.87 & 116.31 & 94.05 & 93.36 & 96.81 \\
\hline
\end{tabular}




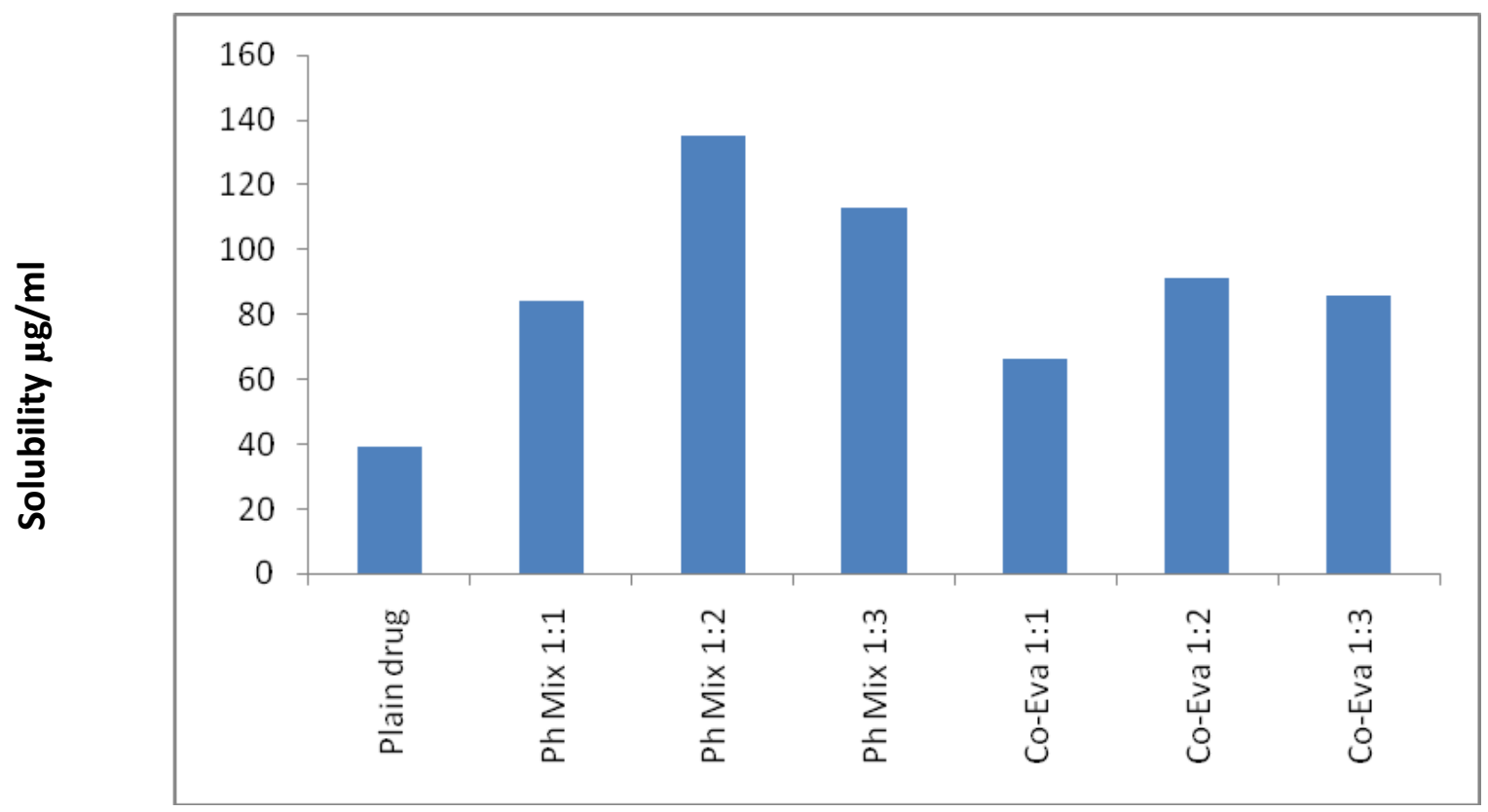

Figure (3) : Solubility of spironolactone, its physical mixtures and its co-evaporates in SGF $\mathrm{pH} 1.2$ at $37 \pm 0.5^{\circ} \mathrm{C}$.

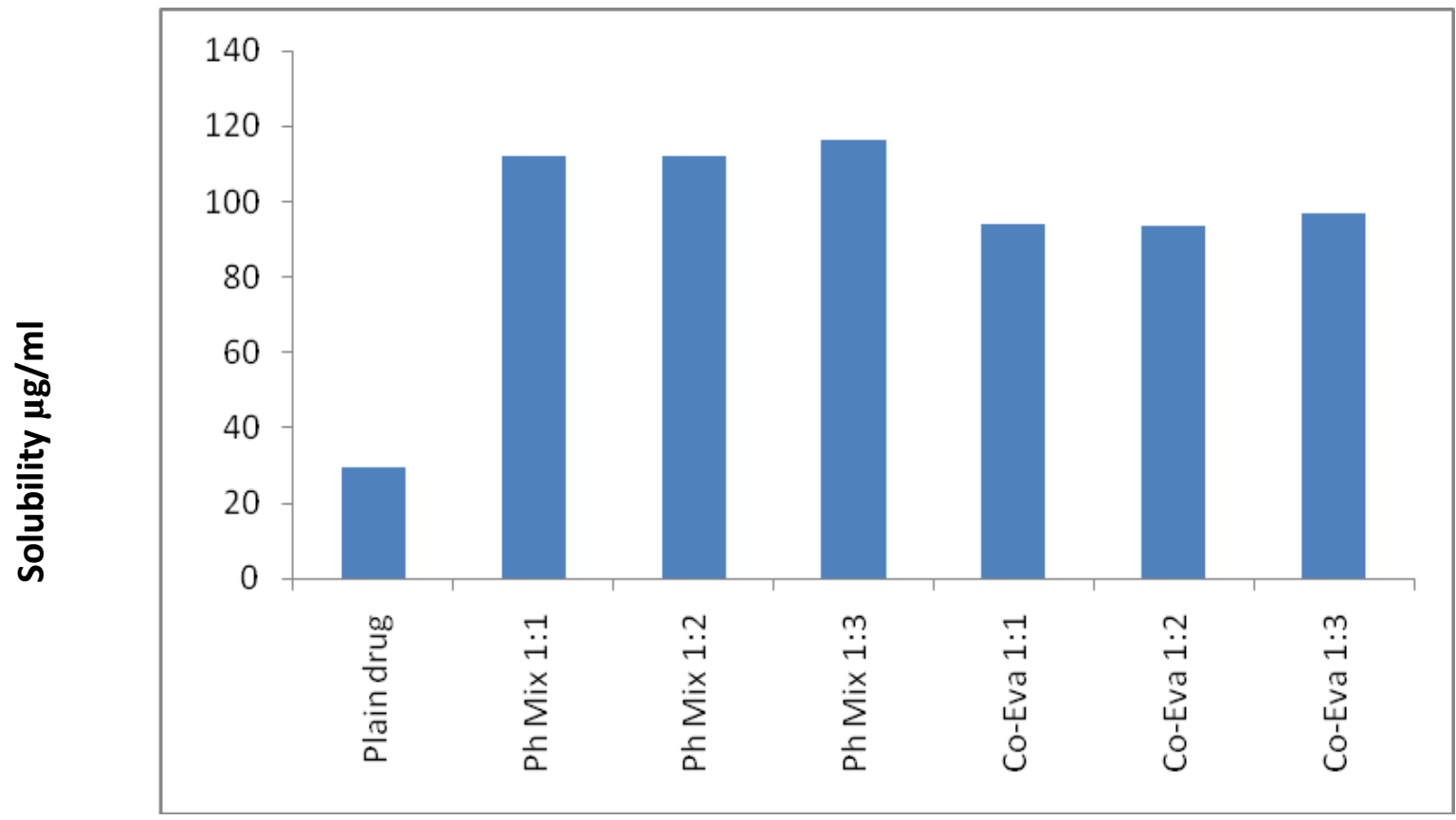

Figure (4): Solubility of spironolactone, its physical mixtures and its adsorbate mixtures in $\mathrm{SIF} \mathrm{pH} 7.5$ at $37^{\circ} \mathrm{C}$.

\section{In-Vitro dissolution studies:}

The results of the dissolution of spironolactone, its physical mixtures and its coevaporates with betacyclodextrin are presented in tables $(3,4)$ and graphically illustrated in figures $(5,6)$. The results showed that the dissolution was increased upon using the physical mixtures or the co-evaporates in both of acidic and basic medium through the first hour of dissolution. The percent released after one hour in case of SGF was 56.12, 64.82, 71.56, $73.85,77.32,65.34$ and 71.47 for plain drug, physical mixtures (1:1, 1:2 and 1:3) and coevaporates (1:1, 1:2 and 1:3), respectively. The percent released after one hour in case of 
SIF was $56.14,59.63,51.28,58.62,60.08,49.68$ and 57.08 for plain drug, physical mixtures (1:1, 1:2 and 1:3) and co-evaporates (1:1, 1:2 and 1:3), respectively. The increased dissolution rate of spironolactone from physical mixtures may be due to the deaggregation of spironolactone clumps achieved by the carriers in the dissolution medium (Kadir et al., 2012, Ismail et al., 2004). The dissolution improvement of spironolactone from solid dispersion might be due to lowering of surface tension between drug and solvent as well as decreased crystallinity of the product (Kalaiselvan et al., 2006). Also the dissolution improvement of the drug in case of the co-evaporate may be attributed to the fact that a portion of the drug has been transformed from the crystalline state to the amorphous one due to the inclusion complexation with betacyclodextrin (Karatas et al., 2005).

Table (3): In-Vitro release of spironolactone, its physical mixtures and its co-evaportaes in $\mathrm{SGF}$ pH 1.2 at $37 \pm 0.5^{\circ} \mathrm{C}$.

\begin{tabular}{|l|c|c|c|c|c|c|c|}
\hline \multirow{2}{*}{ Formula } & \multicolumn{7}{|c|}{ \% released after time interval (min) } \\
\cline { 2 - 8 } & 15 & 30 & 60 & 90 & 120 & 150 & 180 \\
\hline Plain drug & 21.48 & 38.80 & 56.12 & 65.08 & 72.96 & 76.48 & 81.28 \\
\hline Ph mix 1:1 & 30.74 & 44.31 & 64.82 & 72.49 & 80.05 & 82.68 & 88.93 \\
\hline Ph mix 1:2 & 36.79 & 51.90 & 71.56 & 80.63 & 84.81 & 91.22 & 94.42 \\
\hline Ph mix 1:3 & 44.21 & 61.59 & 73.85 & 83.04 & 87.62 & 91.79 & 94.69 \\
\hline Co-eva 1:1 & 33.48 & 56.56 & 77.32 & 79.98 & 84.99 & 91.94 & 92.11 \\
\hline Co-eva 1:2 & 45.88 & 57.24 & 65.34 & 67.78 & 70.50 & 73.74 & 75.37 \\
\hline Co-eva 1:3 & 60.30 & 65.71 & 71.47 & 77.59 & 79.38 & 81.09 & 81.98 \\
\hline
\end{tabular}

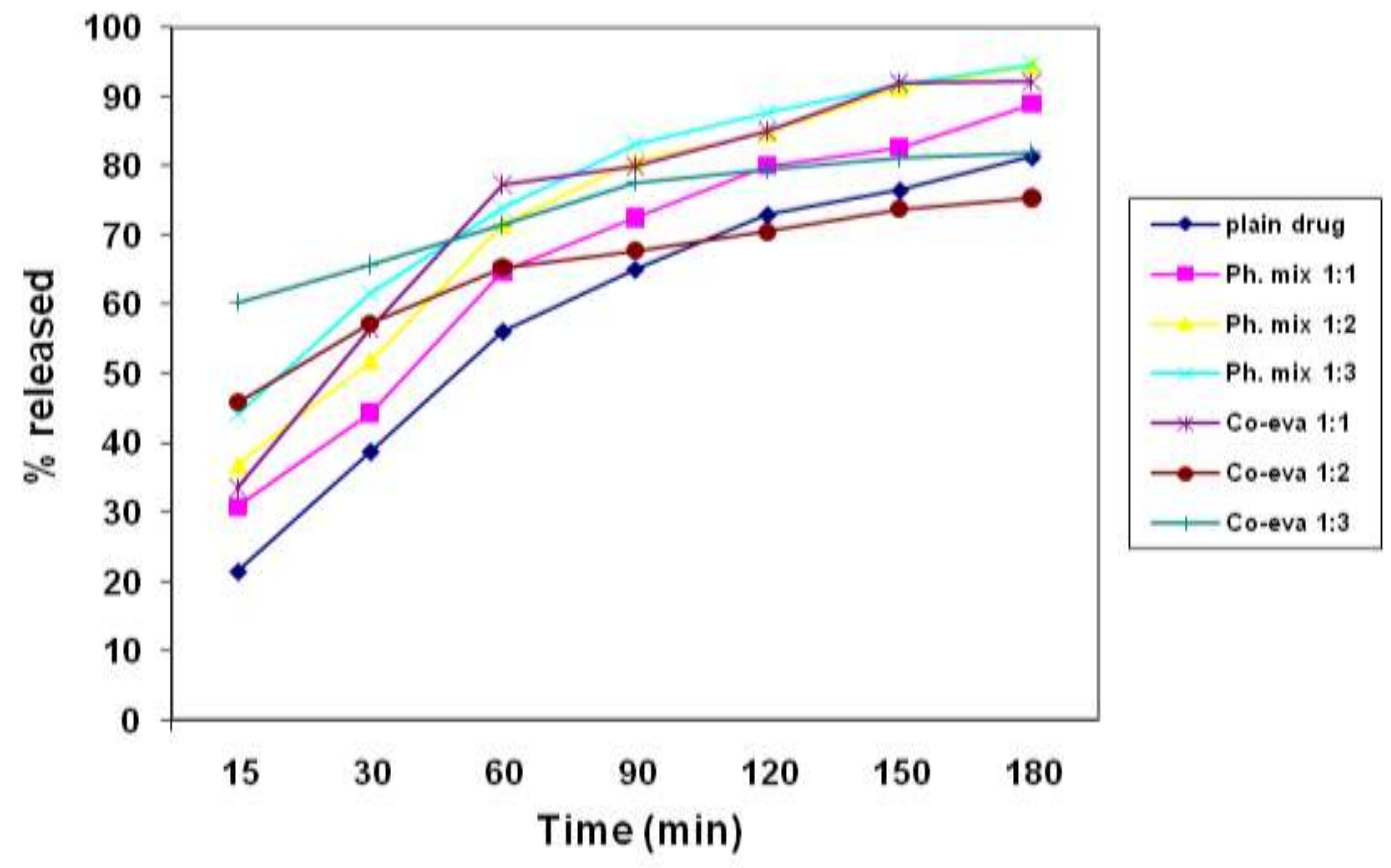

Figure (5): Dissolution profile of spironolactone, its physical mixtures and its co-evaporates in $\mathrm{SGF}$ pH 1.2 at $37 \pm 0.5^{\circ} \mathrm{C}$. 
Table (4): In-Vitro release of spironolactone, its physical mixtures and its co-evaporates in SIF $\mathrm{pH} 7.5$ at $37 \pm 0.5^{\circ} \mathrm{C}$.

\begin{tabular}{|l|c|c|c|c|c|c|c|}
\hline \multirow{2}{*}{ Formula } & \multicolumn{6}{|c|}{ \% released after time interval (min) } \\
\cline { 2 - 8 } & 15 & 30 & 60 & 90 & 120 & 150 & 180 \\
\hline Plain drug & 10.87 & 35.23 & 56.14 & 69.30 & 74.69 & 79.38 & 84.63 \\
\hline Ph mix 1:1 & 15.34 & 32.70 & 59.63 & 67.88 & 74.45 & 75.36 & 76.45 \\
\hline Ph mix 1:2 & 22.14 & 39.44 & 51.28 & 60.67 & 62.23 & 65.31 & 68.40 \\
\hline Ph mix 1:3 & 33.41 & 46.16 & 58.62 & 59.80 & 61.68 & 66.62 & 66.81 \\
\hline Co-eva 1:1 & 17.06 & 47.04 & 60.08 & 64.19 & 68.83 & 69.71 & 70.63 \\
\hline Co-eva 1:2 & 36.29 & 42.32 & 49.68 & 51.94 & 58.20 & 59.13 & 59.81 \\
\hline Co-eva 1:3 & 48.17 & 52.76 & 57.08 & 56.42 & 59.93 & 60.12 & 62.12 \\
\hline
\end{tabular}

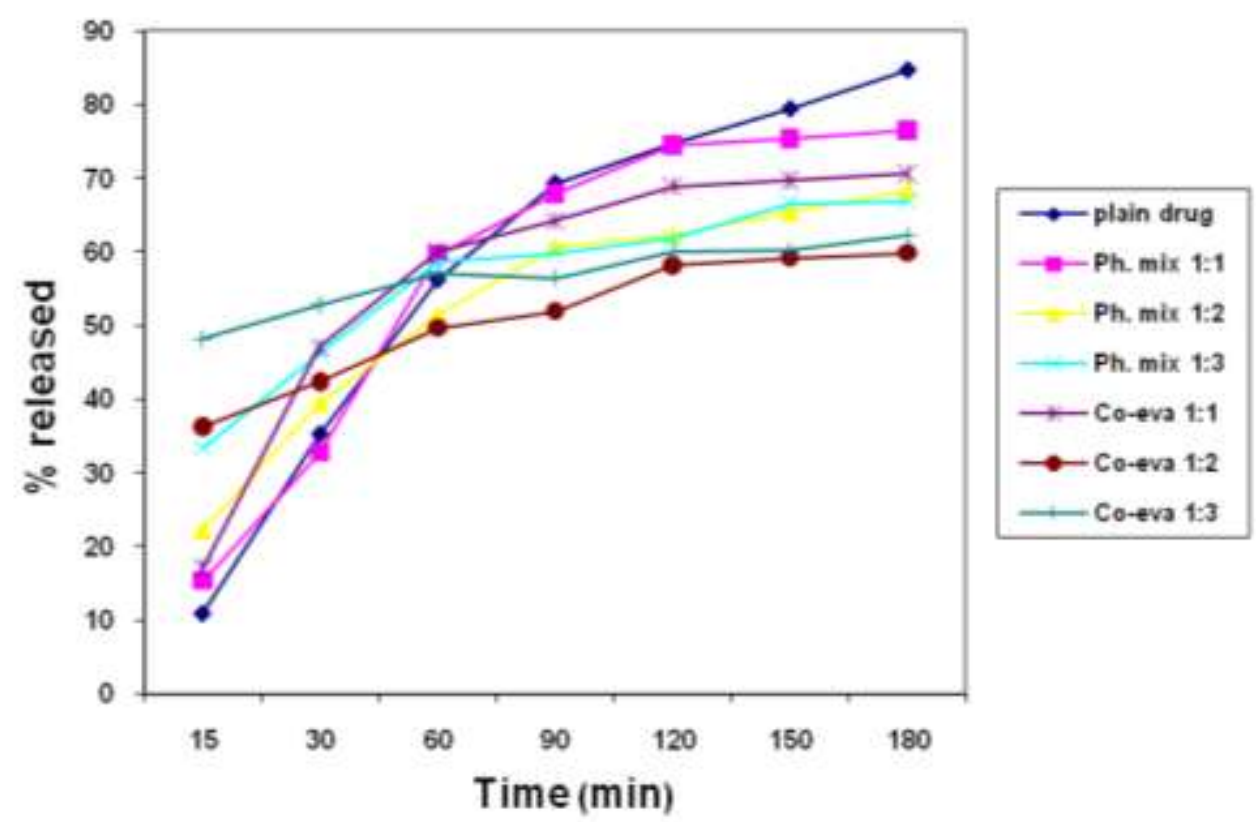

Figure (6): Dissolution profile of spironolactone, its physical mixtures and its co-evaporates in SIF pH 7.5 at $37 \pm 0.5^{\circ} \mathrm{C}$.

\section{CONCLUSION:}

Physical mixtures and co-evaporates of spironolactone and betacyclodextrin were prepared in this work. The physicochemical charaeterization of the systems prepared indacated transformation of the drug from the crystalline form to the amorphous form due to inclusion complexation. The results showed an increase in the solubility values and an improvement in the dissolution pattern of the drug in case of the physical mixtures and the co-evaporates. 


\section{REFERENCES:}

Ahuja, N.; Katare, OP. and Singh, B.; (2007): Studies on Dissolution Enhancement and Mathematical Modeling of Drug Release of a Poorly Water-Soluble Drug Using Water-Soluble Carriers, Eur. J. pharm. Biopharm., 651, 26 - 38.

Chow, A. H. L.; Hsia, C. K.; Gordon, J. D.; Young, J. W. M. and VarghaButler, E. I.; (1995): Assessment of Wettability and its Relationship to the Intrinsic Dissolution Rate of Doped Phenytoin Crystals, Int. J. pharm., 126, 21 - 28.

Duchene, D.; Woussidjewe, D. and Ponchel, G.; (1999): Cyclodextrins and Carrier Systems, J. Control. Release, 62, 263 - 268.

Duncan, Q. M. C.; (2002): The Mechanism of Drug Release from Solid Dispersions in Water-Soluble Polymers, Int. J. Pharm., 231, 131 144.

Fahr, A. and Liu, X.; (2007): Drug Delivery Strategies for Poorly Watersoluble Drug, Expert. Opin. Drug Deliv., 4, 403 - 416.

Gomez-Orellana, I.; (2005): Strategies to Improve Oral Drug Bioavaialbility, Expert. Opin. Drug Deliv., 2, 419 - 433.

Ismail, A.; Saleh, K. I. and Khalaf, S.; (2004): Preparation and Evaluation of Naproxen Adsorbate as an Attempt to Improve Drug Dissolution Characteristics, Bull. Pharm. Sci., Assiut Univ., 27 (1), 53 - 62.

Kadir, M. F.; Rashedul Alam, M.; Bin Rahman, A.; Jhanker, Y. M.; Taiatul Shams and Khan, R.; (2012): Study of Binary and Ternary Solid Dispersion of Spironolactone Prepared by Co-precipitation Method for the Enhancement of Oral Bioavailability, J. App. pharm. Sci., 2 (10), 117 - 122.

Kalaiselvan, R.; Mohanta, G. P.; Manna, P. K. and Manavalan, R.; (2006): Studies on Mechanism of Enhanced Dissolution of Alnedazole Solid Dispersions with Crystalline Carriers, Indian. J. pharm. Sci., 68, 599 $-607$.

Karatas, A.; Nilufer, Y. and Baykara, T.; (2005): Improved Solubility and Dissolution Rate of Piroxicam using Gelucire 44/14 and Labrasol IL., Farmaco., 60, 777 - 782. 
Leuner, C. and Dressman, J.; (2000): Improving Drug Solubility for Oral Delivery Using Solid Dispersions (Review Article), Eur. J. pharm. Biopharm., 50, 47 - 60.

Loftsson, T. and Brewster, M. E.; (1996): Pharmaceutical Applications of Cyc;odextrins: Drug Solubilization and Stabilization, J. pharm. Sci., 85, 1017 - 1025.

Puckhraj Chhaprel; Talesara, A. and Jain, A. K.; (2012): Solubility Enhancement of Poorly Water Soluble Drug Using Spray Drying Technque, Int. J. pharm. Studies \& Res., III,II, 1 - 5.

Purvis, T.; Vaughn, J. M.; Rogers, T. L.; Chen, X.; Over, K. A.; Sinswat P. J.; Hu J. T.; Mc Conville K. P. and Williams, R. O.; (2006): Cryogenic Liquids, Nanoparticles and Microencapsulation, Int. J. pharm., 324, 43 - 50.

Rani, T. R.; Rathore, D. S. and Amit, V.; (2012): Formulation and Evaluation of Oral Dispersible Tablet Containing Spironolactone Hydroxypropyl- $\beta$-Cyclodextrin Binary System, Int. R. J. pharm., 3 (4), $318-323$.

Tanaka, N.; Imai, K.; Okimoto, K.; Jeda, S. R.; Ibuki, Y. T.; Higak, K. and Kimura, T.; (2006): Development of Novel Sustain-Release System Disintegration Controlled Matrix Tablet (DCMT) with Dispersion Granules of Nicladipine (II): In-Vitro Evaluation, J. Controlled Release, 122, 51 - 56.

USP XXIX: US Pharmacopeial Convention, MD, Rockville (2006).

Yonemochi, E.; Kitahara, S.; Maeda, S.; Yamamura, S.; Oguchi, T. and Yamamoto, K.; (1999): Physicochemical Properties of Amorphous Clarithromycin Obtained by Grinding and Spray Drying, Eur. J. pharm. Sci., 7, 331 - 338. 
تأثير البيتاسيكلوديكسترين على ذوبان و إتاحة الإسبيرونولاكتون باستخذام طرق الخلط الفيزيقى و الترسيب بتبخير المذيب الإنيرون

\section{خالد إسماعيل صالح}

$$
\text { قسم الصيدلانيات و الصيدلة الصناعية ـ كلية الصيدلة - جامعة الأزهر - فرع أسيوط }
$$

الاسبيرونولاكتون هو عقار ستيرودى يعمل كمضاد للألدوستيرون ويستخدم كمدر للبول محافظ على

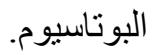

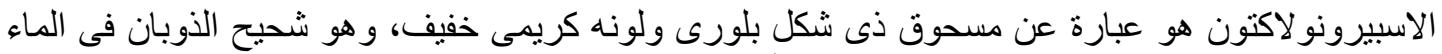

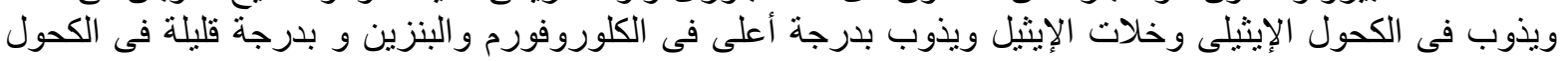

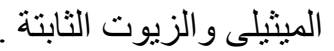

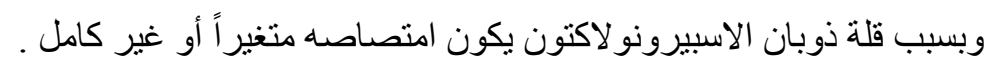

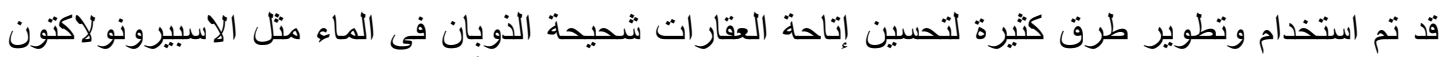

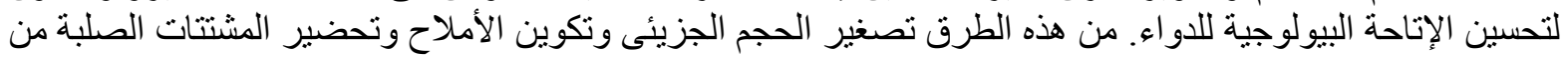

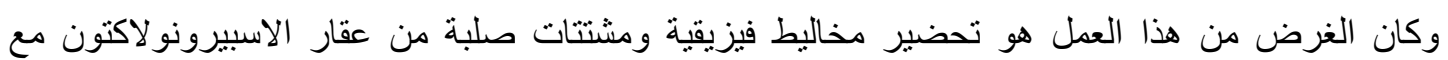

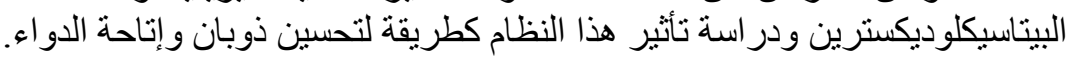

وقد استخدمت طريقة الترسيب بتبخير المذيب لتحضير المشتتات الصلبة من العقار مع البيتاسيكلوديكسترين.

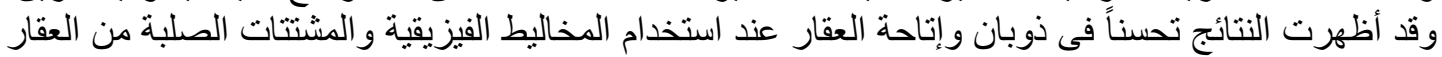

